\title{
SEX AND BLOOD GROUPS AND THE STRUCTURE OF THE RENAL VASCULAR PEDICLE IN MAN
}

KEY WORDS: renal vascular pedicle, sex, blood groups

\section{Henryk Sosnik}

Katarzyna Sosnik*
MD,PhD Department of Pathomorphology, Regional Specialist Hospital, Wroclaw, Poland.

Department of Pathomorphology, Regional Specialist Hospital, Wroclaw, Poland. *Corresponding Author

Background: Kidneys with one renal artery are mostly desired in transplantation. The study investigated the correlation between sex, blood groups, and the anatomy of the renal vascular pedicle. Material and Methods: The study group comprised 322 corpses (176 male and 146 female), where we determined the number of renal arteries and venous renal vascularization anomalies. The obtained results were correlated with sex and blood groups of the investigated individual. Results: A single renal artery occurred significantly more often in female $(105 / 146 ; 72 \%)$ than in man $(95 / 176 ; 54 \%)(p=0.0001)$. The above-mentioned was significantly correlated with the blood groups $(p=0.0476)$. This correlation was not observed in case of the venous system $(p=0.304)$. A single renal artery was mostly observed in blood group O $(140 / 251 ; 55.8 \%)$, most rarely in blood group A $(142 / 321 ; 44.2 \%)$, and intermediate values were observed in blood groups $A B(52.5 \%)$ and B (48.1\%). The $\mathrm{Rh}(+)$ factor has a positive (51.2\%), while the $\mathrm{Rh}(-)$ a negative (39\%) influence on the occurrence of bilateral, single renal arteries $(p=0.014)$. The female sex in a normal renal artery system dominates over the male sex in blood group O (38/48;79.2\% and $32 / 56 ; 57 \%$, respectively) $(p=0.001)$, and blood group B $(24 / 35 ; 68.6 \%$ and $14 / 28 ; 50 \%$, respectively) $(p=0.004)$, and insignificantly more often in case of blood group $A B(10 / 13$; $77 \%$ and $11 / 19 ; 58 \%$, respectively) ( $p=0.14$ ), as well as at the border of significance in case of $A$ blood group (33/52; $63.5 \%$ and $38 / 71 ; 53.5 \%$, respectively) ( $p=0.082$ ). Right-sided venous supernumerary was observed significantly more often in blood group $A(18 / 76 ; 23.7 \%)$, and most rarely in blood group $O(7 / 64 ; 10.9 \%)(p=0.049)$. Conclusions: Female sex significantly positively correlated with single renal artery on both sides. In blood group $O$ there were significantly more cases with bilateral single renal arteries, while in group $A$ the lowest.

\section{Introduction:}

Good knowledge of the structure of the renal vascular pedicle in transplantation is important [1,2]. According to Saldarriaga et al. [3] the above-mentioned fascicle comprised $22.3 \%$, to Pick and Anson 32.25\% [4], while according to Sosnik and Sosnik, even $38.3 \%$ multiple renal arteries [5]. The time of transplantation, warm ischemia, and hypoxia of kidneys with multiple arteries is significantly prolonged, as compared to cases with an isolated artery, and the percentage of vascular complications is higher, which may lead to renal tubular necrosis [6-11].

The available literature contains works related to the influence of blood groups on various pathological changes in the human system [12-15]. We did not find any articles on the correlation between blood groups and the structure of the renal vascular pedicle.

The study determined the correlation between sex ,blood groups, and the number of renal arteries, as well as developmental anomalies of the renal venous system.

\section{Material and methods:}

After obtaining the approval of the Bioethical Committee (Bioethical Committee N. 2/BOPD 2017 DIL), the structure of the renal vascular pedicle was analyzed. The study group comprised 322 deceased patients of different age, including 176 men and 146 women. The kidneys, together with the aorta and vessels were removed entirely from the corpse. The vessels were contrast $\mathrm{x}$-rayed and anatomically prepared. The previous study mentioned the methodology [ 5 ]. The study investigated the correlation between sex, blood groups and the number of renal arteries, as well as developmental anomalies of the renal venous system. Data concerning the type of blood groups were obtained on the basis of clinical files. The obtained results were subject to statistical analysis, based on Statistica 12 Software and Microsoft Excel. Pearson's chi-squared test and test of difference between two proportions were used for calculation.

|www.worldwidejournals.com

\section{Results:}

Tables 1-8 presented the results in three stages:

a) one renal artery on both sides was observed in $(210 / 344$ $61 \%)$ of female and $(190 / 467 ; 40.7 \%)$ of male cases $(\mathrm{p}=0.0001$ (Fig. 1, Tab.1). An additional renal artery was observed in $(171 / 456 ; 37.5 \%)$ male and (105/344; 30.5\%) female cases ( $p=0.07$ ) (Fig.2) (Tab.2). Multiple) renal arteries (4-6) (Fig. 3-5) were observed significantly more often in male $(106 / 467 ; 22.7 \%)$, as compared to female cases $(29 / 344$; $8.43 \%)(p=0.0001)$

b) the presence of a bilateral isolated renal artery significantly varied, depending on the blood groups $(p=0.0476)$. The highest percentage was observed in blood group O $(140 / 251 ; 55.8 \%)$ patients (Tab.4), and the lowest in blood group A $(142 / 32144.24 \%)$ patients $(p=0.001)$ (Tab.3). An additional renal artery was most frequently observed in blood group B patients (63/158; 39.9\%) (Tab.5), and least frequently in blood group $A B(21 / 80 ; 26.3 \%)(p=0.0378)$ (Tab.6). The highest presence of numerous arteries (4-6) was observed in blood group $A(68 / 321 ; 21.2 \%)$ and the lowest in blood group $O(27 / 251 ; 10.8 \%)(p=0.0009)$. The difference between blood groups AB (17/80; $21.3 \%)$ and B (19/158; $12.03 \%)$ was on the border of statistical significance $(p=0.061)$.

c) a single renal artery on both sides was observed significantly more often in female blood group O (71.7\%), as compared to male patients $(44 \%)(p=0.001)$, as well as in female blood group B (59,3\%), as compared to male (36.4\%) $(p=0.004)$. In case of blood group $A$ the above-mentioned was at the border of significance, (50\%) vs. (40.2\%), respectively $(p=0.082)$, while in case of blood group $A B$, insignificantly more often in women (62.5\%), as compared to men $(45.8 \%)$ $(\mathrm{p}=0.14)$.

An additional renal artery was observed insignificantly more often in male blood group $O(p=0.138)$ and $A(p=0.385)$ than in female patients, as well as in female blood group $B$ $(p=0.819)$ than in male patients. On the other hand, in male blood group $A B$ patients, the accessory renal artery was 
significantly more common $(18 / 48 ; 37.5 \%)$, as compared to female patients $(3 / 32 ; 9.4 \%)(p=0.005)$.

Multiple renal arteries (4-6) occurred significantly more often in male blood group 0 patients $(27 / 145 ; 18.6 \%)$, as compared to female cases $(0 \%)(p=0.001)$, as well as in blood group $B$ male cases $(19 / 77 ; 24.7 \%)$, as compared to women $(0 \%)$ $(p=0.001)$.

The above-mentioned phenomenon was observed insignificantly more often in male, blood group A patients $(23.3 \%)$, as compared to female cases $(18.2 \%)(p=0.27)$, while in female blood group $A B$, insignificantly more often $(9 / 32 ; 28 \%)$, as compared to male $(8 / 48 ; 16.7 \%)(p=0.219)$.

$\mathrm{Rh}(+)$ was significantly associated with bilateral, isolated renal artery presence in $51.2 \%(340 / 664)$ of cases, while in case of Rh (-) only in 46/118 (38.98\%) ( $p=0.014)$ (Tab.7). An additional renal artery was diagnosed in case of $\mathrm{Rh}(+)$ in $213 / 664(32.08 \%)$, while in case of $\mathrm{Rh}(-)$ in $48 / 118(40.7 \%)$ $(\mathrm{p}=0.068)$. Multiple renal arteries (4-6) were observed more often in $\mathrm{Rh}(-)(24 / 118 ; 20.3 \%)$ as compared to $\mathrm{Rh}(+)$ carriers $(111 / 664 ; 16.7 \%)(p=0.338)$.

Table 8 presented the blood groups, in comparison to the renal venous system. In the entire material $(p=0.304)$, as well as considering particular developmental anomalies, no significant differences in relation to blood groups were observed $(p=0.260)$. However, venous accessory vessels on the right side in blood group A patients was significantly higher $(18 / 76 ; 23.7 \%)$, as compared to blood group O ( $7 / 64$; $10.9 \%)(p=0.049)$.

\section{Discussion:}

Results of the current study showed that kidneys with one renal artery are observed significantly more often in female, as compared to male patients. This is especially true in case of blood group $O$ and $B$ carriers, and at the border of significance in case of blood group A. It is worth mentioning that the distribution of blood groups in our material was similar to that in the Polish population [16].

The renal artery number is important when selecting the appropriate kidney for laparoscopic procurement $[1,2]$. Kidney transplantation with numerous arteries showed increased percentage of vascular and urological complications, as compared to single renal artery cases $[6,7]$. The first mesonephric arteries were found in the $5.3 \mathrm{~mm}$ embryo. During this period many arteries depart from the aorta in three main clusters: upper retrosuprarenal, middle intrasuprarenal, and inferior presuprarenal, forming the socalled rete arteriosum urogenitale [17]. As the mesonephros enters the lumbar area the lower arteries should be subject to regression, while in the middle of the kidney a single terminal artery should develop.

The $A B O$ group genes are located near the long arm of chromosome 9 and code glycosyltransferases, which catalyze different carboxyl groups for antigen $\mathrm{H}$, creating $\mathrm{A}$ and $\mathrm{B}$ antigens of the ABO system. In this process, the presence of different glycosyltransferase gene enhancers with unknown temporal expression mechanism was found $[18,19]$. However, we are not aware of which factors are responsible for the regression of unnecessary embryonic arteries and the formation of the final renal artery. Perhaps further research in the future will reveal these matters.

$\mathrm{ABH}$ antigens were abundantly represented in tissues of the earliest embryos, and their depletion was associated with morphological differentiation [20]. The deposits of these antigens were presented ultrastructurally in the developing middle ear [21]. There were 7\% more of renal parenchymal diseases in blood group B, and 10\% less in blood group $\mathrm{O}$ carriers as compared to the healthy population [13]. These factors must also somehow influence tissue development. For example Cryptorchidism mostly concerned premature babies from ARh+ and BRh+ mothers [22]

The $\mathrm{Rh}(+)$ factor intensified acquired deafness in industrial workers [23]. In our material, the $\mathrm{Rh}(+)$ factor positively correlated with the presence of kidneys with an isolated artery on both sides.

However, apart from right-sided venous abundancy in blood group A patients, we observed no correlation between blood groups and the structure of the renal venous system. This might be associated (probably) with the small number of investigated cases, and significant number of developmental elements of the venous system and blood groups, to which these factors were referred to.

\section{Conclusions:}

(1) Female gender was significantly correlated with the presence of bilateral single renal arteries.

2) Coexistence of bilateral single renal artery was significantly associated with blood group $O$, and the weakest with blood group $\mathrm{A}$.

(3) $\mathrm{Rh}(+)$ factor significantly correlated with the normal structure of the renal vascular pedicle, and Rh(-) the least.

4) There was no significant association of blood groups and the occurrence of kidney venous system anomalies, except for additional venous vessels on the right side, mostly observed in blood group A patients, least often in blood group 0

\section{Tables:}

Tab. 1. Sex and the number of renal arteries.

\begin{tabular}{|cccccccccc|}
\hline $\begin{array}{c}\text { No. of } \\
\text { renal } \\
\text { arterie } \\
\text { 5 }\end{array}$ & $\begin{array}{c}\text { No. of } \\
\text { bodies }\end{array}$ & $\begin{array}{c}\text { Sum of renal } \\
\text { arteries }\end{array}$ & $\%$ & $\begin{array}{c}\text { No. of } \\
\text { bodies }\end{array}$ & $\begin{array}{c}\text { Sum of renal } \\
\text { arteries }\end{array}$ & $\%$ & $\begin{array}{c}\text { No. of } \\
\text { bodies }\end{array}$ & $\begin{array}{c}\text { Sum of renal } \\
\text { arteries }\end{array}$ & $\%$ \\
\hline 2 (Fig1) & 95 & 190 & 40.7 & 105 & 210 & 61.0 & 200 & 400 & 49.3 \\
3 (Fig 2) & 57 & 171 & 36.6 & 35 & 105 & 30.5 & 92 & 276 & 34.0 \\
4 (FFig) & 18 & 72 & 15.4 & 2 & 8 & 2.3 & 20 & 80 & 9.9 \\
5 (FFig 4) & 2 & 10 & 2.1 & 3 & 15 & 4.4 & 5 & 25 & 3.1 \\
6 (Fig 5) & 4 & 24 & 5.1 & 1 & 6 & 1.7 & 5 & 30 & 3.7 \\
Summary & 176 & 467 & 100.0 & 146 & 344 & 100.0 & 322 & 811 & 100.0 \\
\hline
\end{tabular}

Explanation:\% - percentage

Tab. 2. Blood groups and the number of renal arteries.

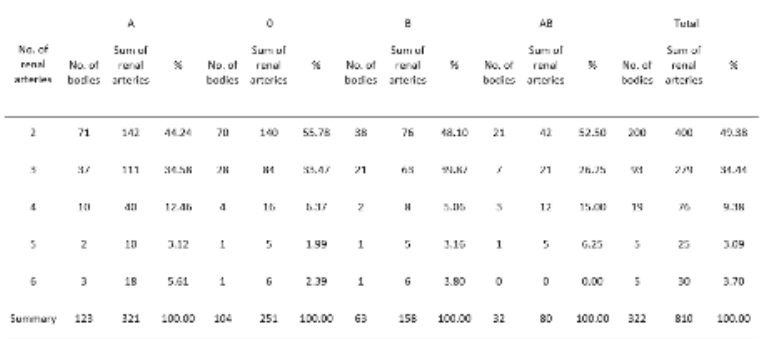

Explanation: A,O,B,AB-blood groups, \%-percetage

Tab. 3. Sex, blood group $A$ and the number of renal arteries.

\begin{tabular}{|c|c|c|c|c|c|c|c|c|c|}
\hline \multirow[b]{2}{*}{ 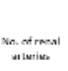 } & \multicolumn{3}{|c|}{ MNer } & \multicolumn{3}{|c|}{ Femande } & \multicolumn{3}{|c|}{ Thatal } \\
\hline & $\begin{array}{c}\text { Re. } \\
\text { maxims }\end{array}$ & $\begin{array}{c}\text { Sum diveul } \\
\text { ntremime }\end{array}$ & * & $\begin{array}{c}\text { No. of } \\
\text { bentibe }\end{array}$ & 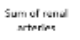 & s & $\begin{array}{c}\text { No. of } \\
\text { berditu }\end{array}$ & $\begin{array}{l}\text { Sum ef rome } \\
\text { Noterise }\end{array}$ & s \\
\hline 2 & 38 & 76 & $\angle a 21$ & 39 & 56 & 50.00 & $n$ & 142 & 44.24 \\
\hline 3 & 2 & nos & 20.51 & 14 & 47 & 3n., & 37 & 11 & 3.5 \\
\hline 4 & 8 & 32 & 16.93 & 2 & 8 & 6.06 & 10 & 40 & 12.45 \\
\hline$=$ & a & $a$ & coun & 2 & w & $\therefore \mathrm{sk}$ & , & w & s.17 \\
\hline 6 & 2 & 12 & 6.35 & 1 & 6 & 4.55 & 3 & 18 & 5.61 \\
\hline Summery & 31 & 168) & 100.00 & 52 & 192 & $100, \infty$ & 123 & 321 & 100.00 \\
\hline
\end{tabular}

Explanation:see tab.1 
Tab. 4. Sex, blood group $O$ and the number of renal arteries.

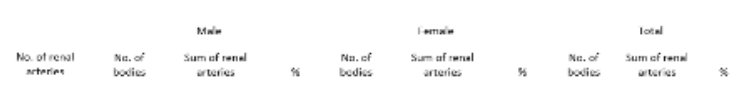

Explanation:see tab.1

Tab. 5. Sex, blood group $B$ and the number of renal arteries.

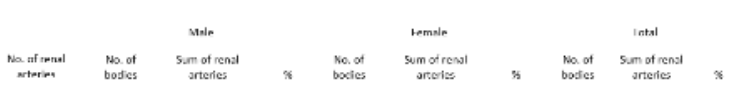

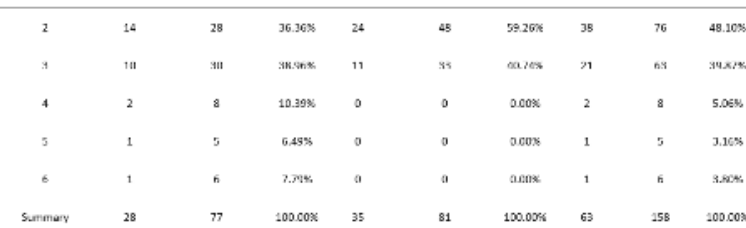

Explanation:see tab. 1

Tab. 6. Sex, blood group AB and the number of renal arteries.

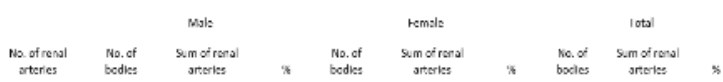

Explanation:see tab. 1

Tab. 7. Rh- factor and the number of renal arteries in Polish population.

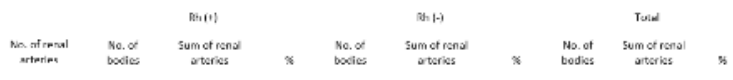

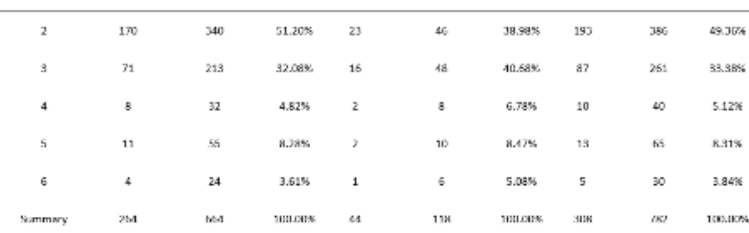

\begin{tabular}{|c|c|c|c|c|c|c|c|c|c|c|}
\hline \multirow[t]{2}{*}{ Blood groups: } & \multicolumn{2}{|c|}{ o } & \multicolumn{2}{|c|}{ A } & \multicolumn{2}{|c|}{ в } & \multicolumn{2}{|c|}{ AB } & \multicolumn{2}{|c|}{ Total } \\
\hline & N & $\%$ & n & $\%$ & N & $\%$ & N & $\%$ & N & \% \\
\hline $\begin{array}{l}\text { Single renal vein on } \\
\text { both sides }\end{array}$ & 47 & 73,4 & 47 & 61,8 & 33 & 71,7 & 9 & 60,0 & 136 & 67,7 \\
\hline $\begin{array}{l}\text { Venous } \\
\text { supernumerary on the } \\
\text { right } \\
\text { venous }\end{array}$ & 7 & 10,9 & 18 & 23,7 & 7 & 15,2 & 3 & 20,0 & 35 & 17,4 \\
\hline $\begin{array}{l}\text { supernumerary and } \\
\text { vena cava inferior } \\
\text { anomalies on the left }\end{array}$ & 8 & 12,5 & 5 & 6,6 & 6 & 13,0 & 2 & 13,3 & 21 & 10,4 \\
\hline \begin{tabular}{|l} 
Bilateral venous renal \\
anomalies
\end{tabular} & 2 & 3,1 & ${ }^{6}$ & 7,9 & 0 & 0,0 & 1 & 6,7 & 9 & 4,5 \\
\hline Total of anomalies & 17 & 26,6 & 29 & 38,2 & 13 & 28,3 & 6 & 40,0 & 65 & 32,3 \\
\hline Total of bodies & 64 & 100,0 & 76 & 100,0 & 46 & 100,0 & 15 & 100,0 & 201 & 100,0 \\
\hline
\end{tabular}

Explanation: $\mathrm{Rh}(+), \mathrm{Rh}(-)$ - blood factors $\mathrm{Rh}+$ and $\mathrm{Rh}-, \%-$ percentage

Tab. 8. Blood groups and renal venous anomalies.
Explanation: $\mathrm{N}$ - number, \% - percentage, O,A,B,AB - blood groups

Figures:

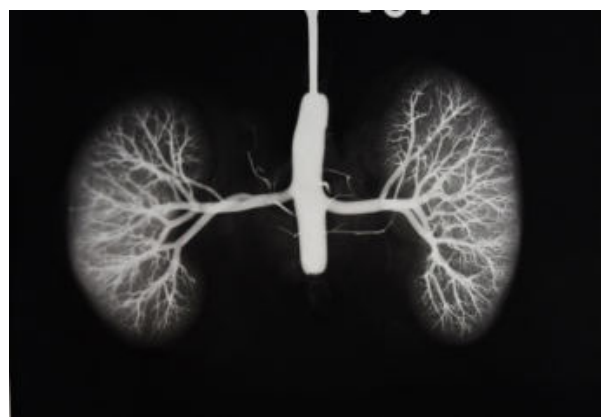

Fig 1. Aortonephrogram with a single renal artery visible on both sides.

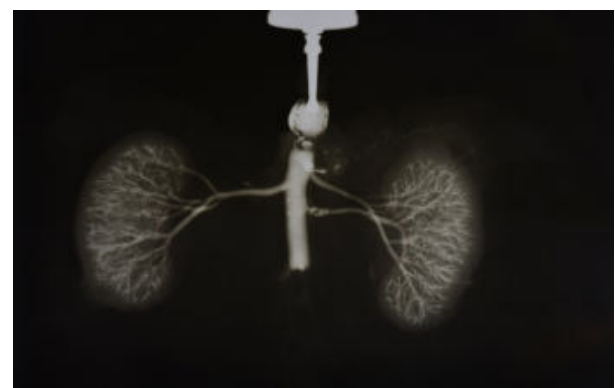

Fig 2. Aortonephrogram with 2 renal arteries visible on the left and a single one on the right side.

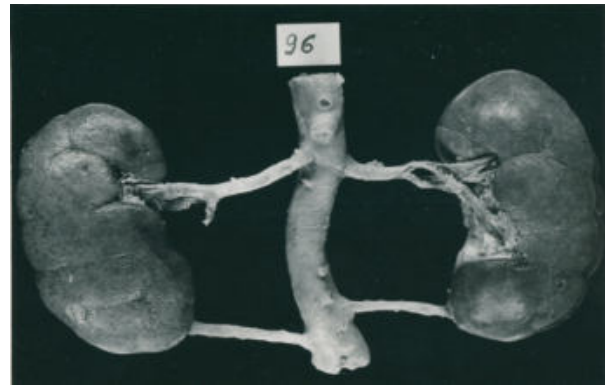

Fig 3. Anatomical specimen. Two renal arteries are visible on both sides.

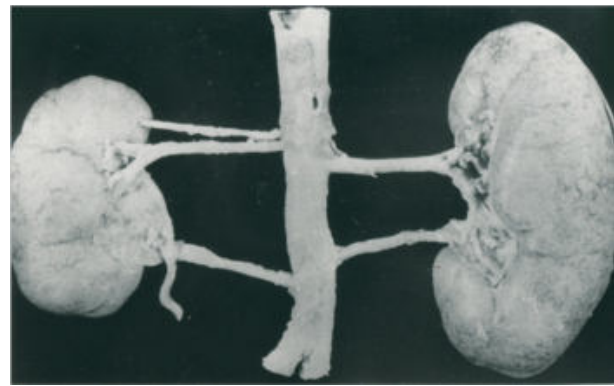

Fig 4. Anatomical preparation. Two renal arteries are visible on the left and 3 on the right side.

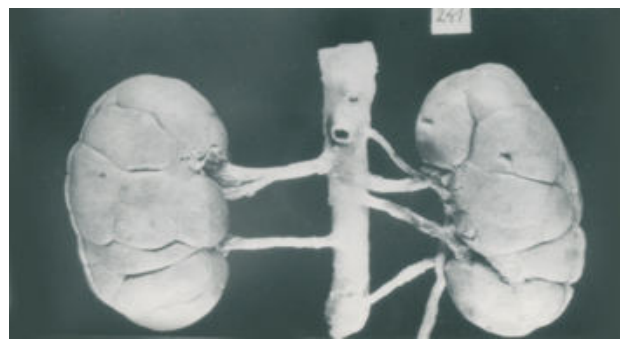

Fig 5. Anatomical preparation. On the left side there are 4 renal arteries and on the right side there are 2 of them. 


\section{References:}

1. He B, Hamdorf JM: Clinical importance of anatomical variations of renal vasculature during laparoscopic donor nephrectomy. OA Anatomy 2013,1(3):25 p 1-7

2. Khamanarong K, Prachaney P, Utraravichien A, Tong - Un T, Sripaoraya K: Anatomy of renal arterial supply. Clin. Anat.2004,17:334-336.

3. Saldarriaga B, Pérez A.F, Ballesteros L.E: A direct anatomical study of additional renal arteries in a Colombian mestizo population. Folia Morphol.2008,67:129-134.

4. Pick J.W, Anson B.J. The renal vascular pedicle. An anatomical study of 430 body-halves.J.Urol, 1940, 44:411-434.

5. Sosnik H, Sosnik K. Investigations on renal vascularisation pathology in the Polish population. 1.Incidence of multiple kidney arteries. Folia Morphol. 2017,76:226-231.DOI:10.5603/FM.a.2016.0073

6. Ashraf H.S, Hussain I, Siddiqui A.A, Ibrahim M.N, Khan M.U. The outcome of living related kidney transplantation with multiple renal arteries. Saudi J Kidney Dis Transplant 2013,24:615-619.

7. Carter J.T, Freise Ch.E, McTaggart R.A, Mahanty H.D, Kang S-M, Chan S.H, Feng S, Roberts J.P, Posselt A.M: Laparoscopic procurement of kidneys with multiple renal arteries is associated with increased ureteral complications in the recipient.Am JTransplant 2005, 5:1312-1318.

8. Ghazanfar A, Tavakoli A, Zaki M.R, Pararajasingam R, Campbell T, Parrott N.R Augistine T, Riad H.N: The outcomes of living donor renal transplants with multiple renal arteries: $A$ large cohort study with a mean follow-up period of 10 years. Transplant Proc. 2010,42: 1654-1658.

9. Keller J.E, Dolce Ch. J, Griffin D, Heniford B.T, Kercher K.W: Maximizing the donor pool: use of right kidneys and kidneys with multiple arteries for live donor transplantation. Surg Endosc 2009,23: 2327-2331.doi:10.1007/s00464009-0330-9.

10. Paragi P.R, Klaassen Z, Fletcher H.S, Tichauer M, Chamberlain R.S, Wellen J R, Sun H, Geffner S. Vascular constraints in laparoscopic renal allograft: Comparative analysis of multiple and single renal arteries in 976 laparoscopic donor nephrectomies. World J Surg 2011,35: 21592166.doi:10.1007/s00268-011-1168-6.

11. Zorgdrager M, Krikke Ch, Hofker S H, Leuvenink H G D, Pol R A. Multiple renal arteries in kidney transplantation: A systematic review and meta- analysis: AnnTransplant 2016,21:469 - 478.DOI:10.12659/AOT. 898748.

12. Jaff M S : Relation between $A B O$ blood groups and Helicobacter pylori infection in symptomatic patents. Clin Exp Gatroenterol ,201 1,4:221-226.

13. Hamed I A, Mandal A K, Parker D, Czerwinski A W, Mask D R, Wenzl J E: ABO blood groups and renal disease. Ann Clin Lab Sci 1979, 9:524-526.

14. Arslan B, Gürkan O, Cetin B, Arslan Ö A, Göv T, Yazici G, Eroglu T, Avci M A Ozdemir E: Evaluation of $A B O$ blood groups and blood-based biomarkers as a predictor of growth kinetics of renal angiomyolipoma. Int Urol Nephrol 2018,50:2131-2137.DOI.org/10.1007/s1 1255-018-202-9.

15. Hakomori S. Antigen structure and genetic basis of histo-blood groups $A, B$ and O: Their changes associated with human cancer. Biochim Biophys Acta 1999,1473:247-266.doi:10.1016/s0304-4165(99)00183x.

16. Hirszfeld L.: General Immunology (Polish), Spóldzielnia Wydawnicza Czytelnik, 1948:p392.

17. Gillaspie C, Miller L I, Baskin M. Anomalous renal vessels and their surgical significance. Anat Rec 1916,11:77-86

18. Ling X, ZhengY,Tao J,Zheng Z, Chen L: Association study of polymorphisms in the $A B O$ gene with ischemic stroke in the Chinese population. BMC Neurology,2016, 16:146-151,DOI 10.1186/s12883-016-0671-7.

19. Yu L-Ch, Chang C-Y, Twu Y-Ch, Lin M. Human histo-blood group ABO glycosyltransferase genes: Different enhancer structures with different transcriptional activities. Biochem Biophys Res Comm 2000, 273:459 466.doi:10.1006/bbrc.2000.2969.

20. Szulman A E. The histological distribution of the blood group substances in man as disclosed by immunofluorescence. III. The $A, B$, and $\mathrm{H}$ antigens in embryos and fetuses from $18 \mathrm{~mm}$ in length.J Exp Med 1964,119:503-516.

21. Remezal M, Gil-Loyzaga P, Oriol R: Ultrastructural localization of H-human -blood -group immunoreactivity rat cochlear hair cells. ORL J Otorhinolaryngol Relat Spec 1993,55 (4):205-207.doi: 10.1159/000276423.

22. Ghirri P, Ciulli C, Vuerich M, Cuttano A, Faraoni M, Guerrini L, Spinelli C, Tognetti S, Boldrini A.: Incidence at birth and natural history of cryptorchidism: A study of 10,730 consecutive male infants. J Endocrinol Invest 2002,25:709-715.

23. Aycicek A, Sargm R, Kenar F, Dereköy F S.: Can Rh antigens be a risk factor in noise-induced hearing loss? Eur Arch Otorhinolaryngol 2009, 266: 363-366. Doi 10.1007/s00405-008-0753-2. 